\title{
EQUIVALENT CIRCUIT MODELING OF SLOTTED MICROSTRIP PATCH ANTENNA
}

\author{
Parul Bansal $^{1}$, Ekambir Sidhu $^{2}$, Sonia Goyal ${ }^{3}$ \\ ${ }^{1}$ M.Tech Student, Department of Electronics and Communication Engineering, Punjabi University, Patiala, India \\ ${ }^{2}$ Assistant Professor, Department of Electronics and Communication Engineering, Punjabi University, Patiala, India \\ ${ }^{3}$ Assistant Professor, Department of Electronics and Communication Engineering, Punjabi University, Patiala, India
}

\begin{abstract}
In this paper, two slotted Microstrip patch antennas, one is circular slotted and other is rectangular slotted antenna, has been studied and their equivalent circuit modeling has been done. The equivalent circuit modeling has been carried out using RF toolbox of MATLAB. In this, series RLC resonant circuit is used to get the desired $S_{11}$ response for the both the proposed antennas. The equivalent model for both the antennas consists of four series band pass filters in a parallel combination with different values of $R, L$ and $C$.
\end{abstract}

Keywords: Slotted Microstrip Patch Antenna, Equivalent Circuit Modeling, Series RLC resonant circuit, RF Toolbox (MATLAB), $S_{11}$ response.

\section{INTRODUCTION}

Microstrip patch antenna basically consists of three main components- radiating patch, dielectric substrate and a ground plane. The patch is generally made of conducting material such as copper or gold and the substrate material should have particular dielectric constant [1]. Microstrip patch antenna has many advantages such as low cost, easy to manufacture, low weight, comfortable to planar and non planar surfaces [2]. These advantages of the microstrip patch antenna over conventional antenna make them popular to be used for various wireless applications like satellite application, wireless applications, and military applications [3]. The Microstrip patch antenna can be modeled and analyzed in terms of Cavity model or Transmission line model [4].

In this paper, the microstrip patch antenna has been effectively modeled in terms of series RLC resonant circuit. The $S_{11}$ response of the designed and fabricated antennas has been analyzed and then their equivalent circuit modeling has been carried out using series RLC circuit. The series RLC circuit acts as band pass filter that can pass certain resonant frequencies and reject other frequencies. The $S_{11}$ response of both the fabricated antennas has been compared with the equivalent circuit $S_{11}$ response. The proposed equivalent circuit model of an antenna consists of four series RLC circuits of suitable values of resistors, capacitors and inductors connected in parallel.

\section{GEOMETRY OF DESIGNED ANTENNAS}

Fig -1a and Fig -1b shows the geometry of the notched circular slotted antenna showing the front and the bottom view respectively. The patch is rectangular and there is a circular slot on it with notches and the ground plane is reduced. The antenna has been designed and simulated using
CST MWS 2010. Similarly, Fig -2a and Fig -2b shows the front and the bottom view respectively for the rectangular slotted MPA having rectangular patch with rectangular slot on it. The dimensions of the designed antennas have been mentioned in Table -1 and Table - 2 . The antennas have also been fabricated and tested using Network analyzer (E5071C ENA series) [5].

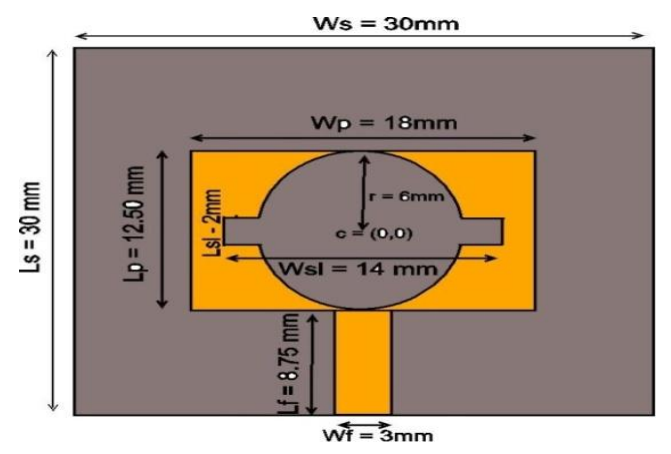

Fig -1a: Top view of notched circular slotted MPA [5]

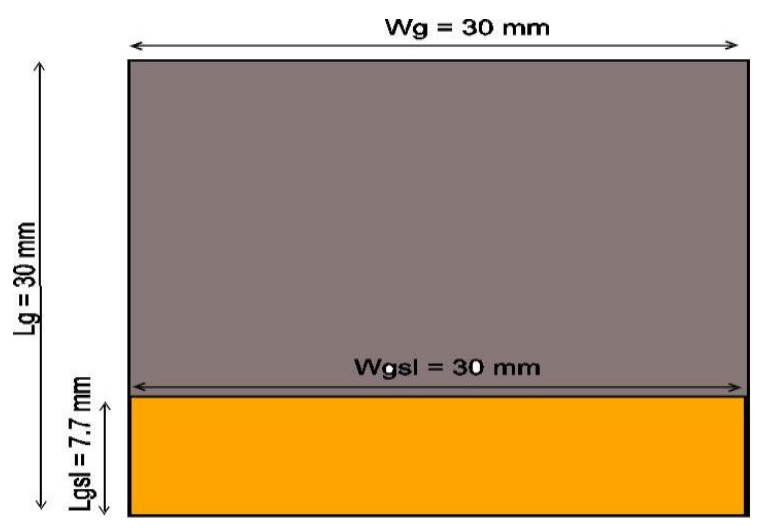

Fig -1b: Bottom view of notched circular slotted MPA [5] 


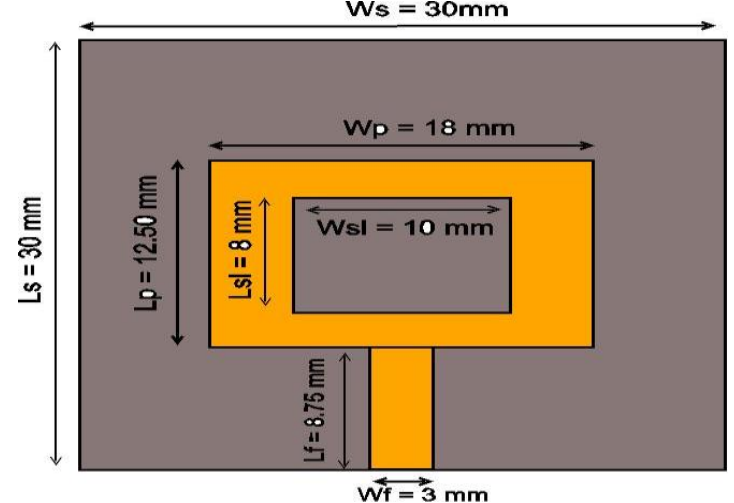

Fig -2a: Top view of rectangular slotted MPA [5]

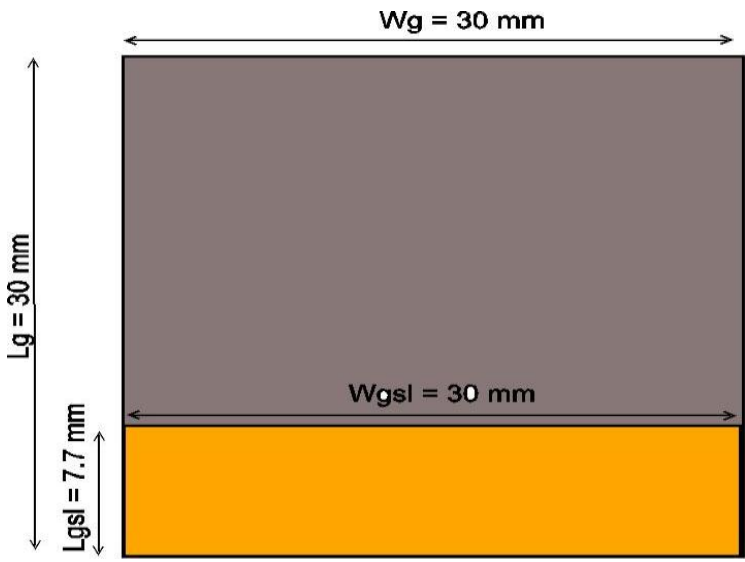

Fig -2b: Bottom view of rectangular slotted MPA [5]

Table -1: Dimensions of notched circular slotted MPA [5]

\begin{tabular}{|c|c|}
\hline Antenna Parameter & Specification \\
\hline Length of substrate & $30 \mathrm{~mm}$ \\
\hline Width of substrate $\quad\left(\mathrm{W}_{\mathrm{s}}\right)$ & $30 \mathrm{~mm}$ \\
\hline Length of Patch & $12.50 \mathrm{~mm}$ \\
\hline Width of Patch & $18 \mathrm{~mm}$ \\
\hline Length of feed & $8.75 \mathrm{~mm}$ \\
\hline Width of feed & $3 \mathrm{~mm}$ \\
\hline Radius of circular slot (r) & $6 \mathrm{~mm}$ \\
\hline $\begin{array}{l}\text { Coordinates of Centre of } \\
\text { circle } \\
\text { ( c ) }\end{array}$ & $(0,0)$ \\
\hline $\begin{array}{l}\text { Length of rectangular } \\
\text { notch in circle }\end{array}$ & $2 \mathrm{~mm}$ \\
\hline $\begin{array}{l}\text { Width of rectangular notch } \\
\text { in circle }\end{array}$ & $14 \mathrm{~mm}$ \\
\hline
\end{tabular}

Table -2: Dimensions of Rectangular slotted MPA [5]

\begin{tabular}{|l|l|}
\hline Antenna Parameter & Specification \\
\hline Length of substrate $\left(\mathrm{L}_{\mathrm{s}}\right)$ & $30 \mathrm{~mm}$ \\
\hline Width of substrate $\left(\mathrm{W}_{\mathrm{s}}\right)$ & $30 \mathrm{~mm}$ \\
\hline Length of Patch $\quad\left(\mathrm{L}_{\mathrm{P}}\right)$ & $12.50 \mathrm{~mm}$ \\
\hline Width of Patch $\quad\left(\mathrm{W}_{\mathrm{p}}\right)$ & $18 \mathrm{~mm}$ \\
\hline Length of feed $\quad\left(\mathrm{L}_{\mathrm{f}}\right)$ & $8.75 \mathrm{~mm}$ \\
\hline Width of feed $\quad\left(\mathrm{W}_{\mathrm{f}}\right)$ & $3 \mathrm{~mm}$ \\
\hline
\end{tabular}

\begin{tabular}{|lc|l|}
\hline Length of slot $\quad(\mathrm{Lsl})$ & $8 \mathrm{~mm}$ \\
\hline Width of slot $\quad(\mathrm{Wsl})$ & $10 \mathrm{~mm}$ \\
\hline
\end{tabular}

\section{SIMULATED AND PRACTICAL S11 RESPONSES OF THE DESIGNED ANTENNAS}

Fig -3 and Fig -4 shows the simulated Return loss $\left(\mathrm{S}_{11}\right)$ plot of notched circular slotted and rectangular slotted MPA. From the simulated results, it can be observed that the return loss is $-41.57 \mathrm{~dB}$ at $4.5 \mathrm{GHz}$ and $-46.78 \mathrm{~dB}$ at $6.2 \mathrm{GHz}$ for notched circular slotted MPA and for rectangular slotted MPA, return loss is $-26.45 \mathrm{~dB}$ at $4.7 \mathrm{GHz}$ and $-24.36 \mathrm{~dB}$ at $6.2 \mathrm{GHz}$. The bandwidth is $2.7 \mathrm{GHz}$ for both the antennas.

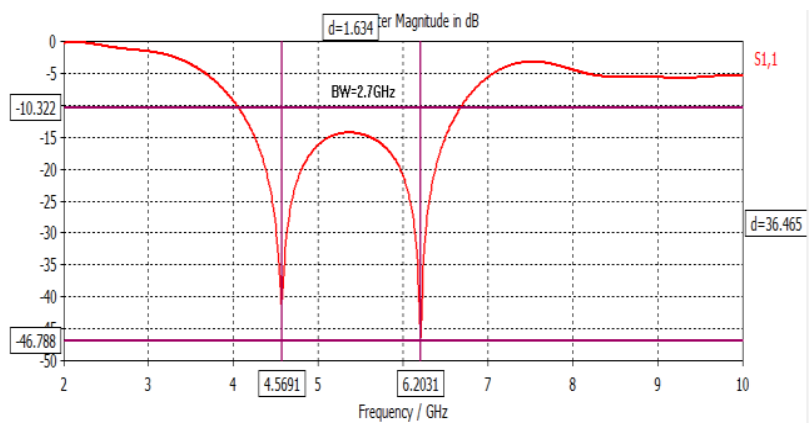

Fig -3: Return loss plot of notched circular slot MPA [5]

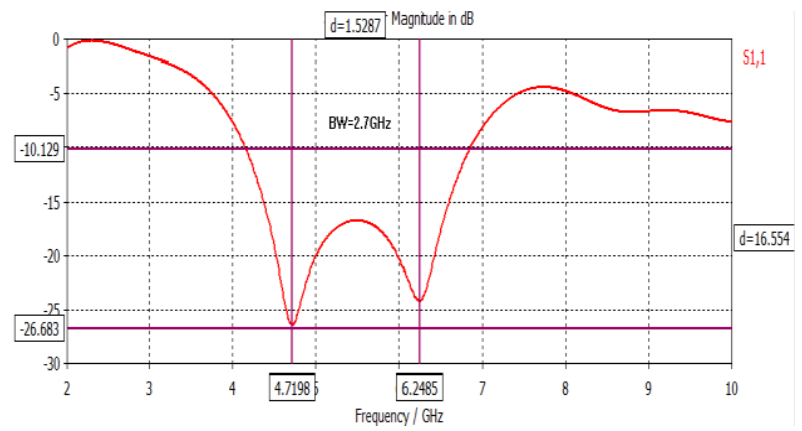

Fig -4: Return loss plot of rectangular slot MPA [5]

Fig -5 and Fig -6 shows the practical $S_{11}$ response carried out using Network Analyzer (E5071C ENA series) for both the designed antennas [5].

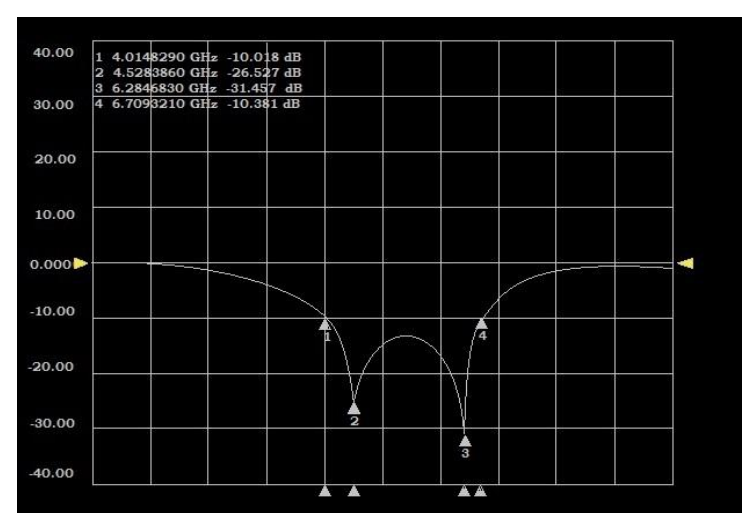

Fig -5: Practical $S_{11}$ response of notched circular slotted MPA using network analyzer [5] 


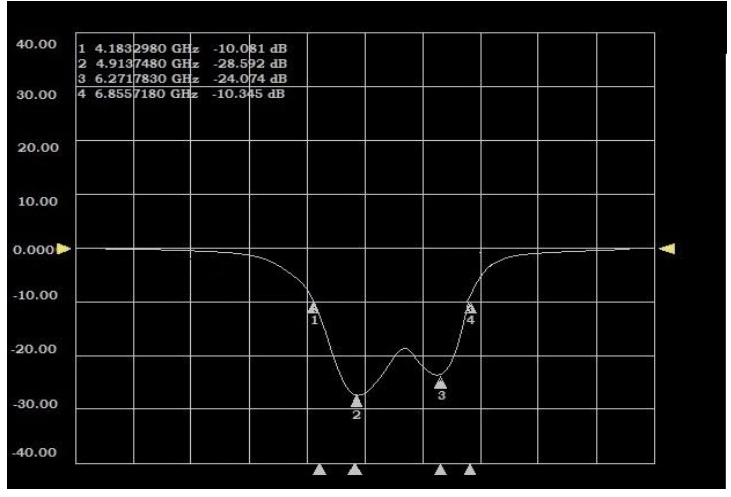

Fig -6: Practical $S_{11}$ response of rectangular slotted MPA using network analyzer [5]

\section{EQUIVALENT CIRCUIT MODELING}

Equivalent circuit model of return loss plot for Microstrip patch antenna can be achieved effectively by using series RLC circuit. The modeling has been done using RF toolbox of MATLAB. The Fig -7 shows a series RLC circuit comprising of $\mathrm{R}, \mathrm{L}$ and $\mathrm{C}$ connected in series. A series resonant circuit can be considered as a Band pass filter which passes certain frequencies and attenuates all other frequencies.

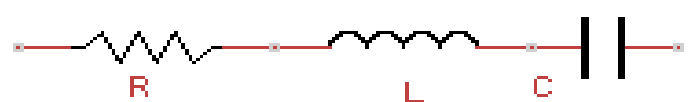

Fig -7: Series RLC circuit

The following equations show the relationship of resonant frequency and bandwidth with $\mathrm{R}, \mathrm{L}$ and $\mathrm{C}$.

$$
\begin{gathered}
f_{r}=\frac{1}{2 \pi \sqrt{L C}} \\
B W=\left(\frac{f_{r}}{2 \pi f L} \times R\right)
\end{gathered}
$$

Fig -8 and Fig -9 shows the equivalent circuit of notched circular slotted MPA and rectangular slotted MPA. It consists of four series RLC circuit connected in parallel with different values of $\mathrm{R}, \mathrm{L}$, and $\mathrm{C}$ which is equivalent to connecting four band pass filters in parallel network as shown in Figure 10. The values of $\mathrm{R}, \mathrm{L}$ and $\mathrm{C}$ for both the circuits have been mentioned in Table -3 and Table -4 respectively.

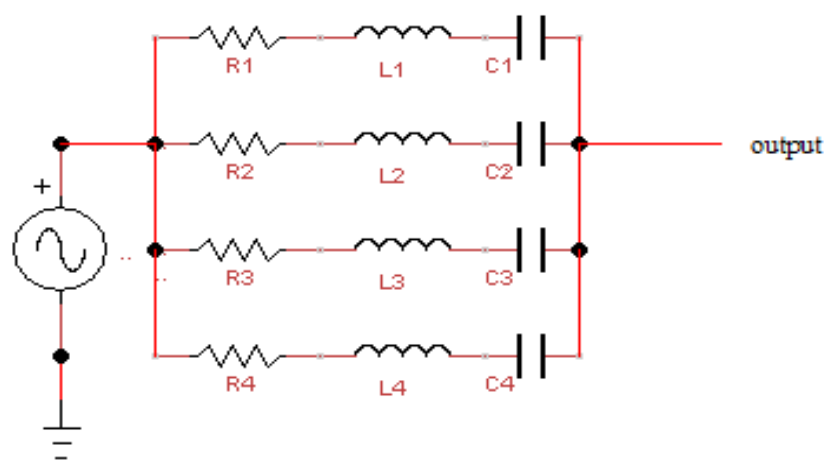

Fig -8: Equivalent circuit for notched circular slotted MPA

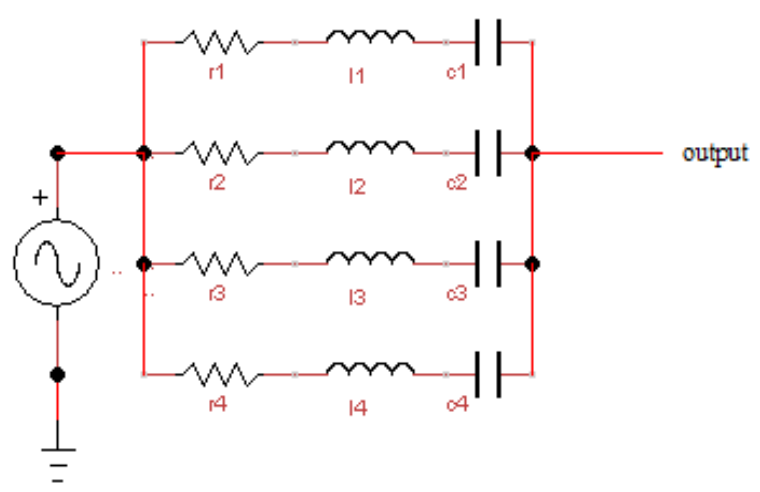

Fig -9: Equivalent circuit for rectangular slotted MPA

Table -3: RLC circuit values for rectangular slotted MPA

\begin{tabular}{|l|l|l|}
\hline Resistance & Inductance & Capacitance \\
\hline $\mathrm{R} 1=3 \mathrm{ohm}$ & $\mathrm{L} 1=9 \mathrm{nH}$ & $\mathrm{C} 1=130 \mathrm{fF}$ \\
\hline $\mathrm{R} 2=4 \mathrm{ohm}$ & $\mathrm{L} 2=20 \mathrm{nH}$ & $\mathrm{C} 2=33 \mathrm{fF}$ \\
\hline $\mathrm{R} 3=55 \mathrm{ohm}$ & $\mathrm{L} 3=9 \mathrm{nH}$ & $\mathrm{C} 3=110 \mathrm{fF}$ \\
\hline $\mathrm{R} 4=50 \mathrm{ohm}$ & $\mathrm{L} 4=7.4 \mathrm{nH}$ & $\mathrm{C} 4=100 \mathrm{fF}$ \\
\hline
\end{tabular}

Table -4: RLC circuit values for rectangular slotted MPA

\begin{tabular}{|l|l|l|}
\hline Resistance & Inductance & Capacitance \\
\hline $\mathrm{r} 1=4 \mathrm{ohm}$ & $11=5 \mathrm{nH}$ & $\mathrm{c} 1=210 \mathrm{fF}$ \\
\hline $\mathrm{r} 2=1 \mathrm{ohm}$ & $12=30 \mathrm{nH}$ & $\mathrm{c} 2=23 \mathrm{fF}$ \\
\hline $\mathrm{r} 3=50 \mathrm{ohm}$ & $13=9 \mathrm{nH}$ & $\mathrm{c} 3=98 \mathrm{fF}$ \\
\hline $\mathrm{r} 4=40 \mathrm{ohm}$ & $14=13 \mathrm{nH}$ & $\mathrm{c} 4=55 \mathrm{fF}$ \\
\hline
\end{tabular}

Fig -10 and Fig -11 shows the $S_{11}$ response of equivalent circuit for notched circular slotted MPA and rectangular slotted MPA respectively. The $S_{11}$ response for both the antennas carried out using series RLC resonant circuit has been matched with the practical results, taken using network analyzer. 


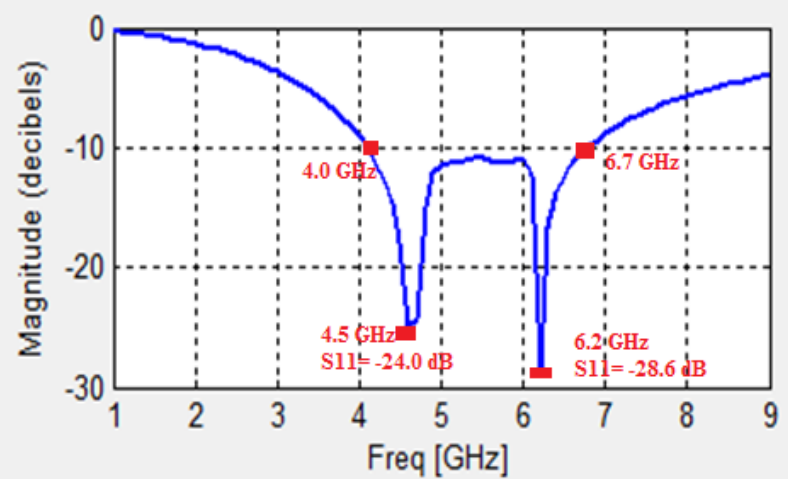

Fig -10: Return loss $\left(S_{11}\right)$ plot of equivalent circuit model for circular slotted MPA

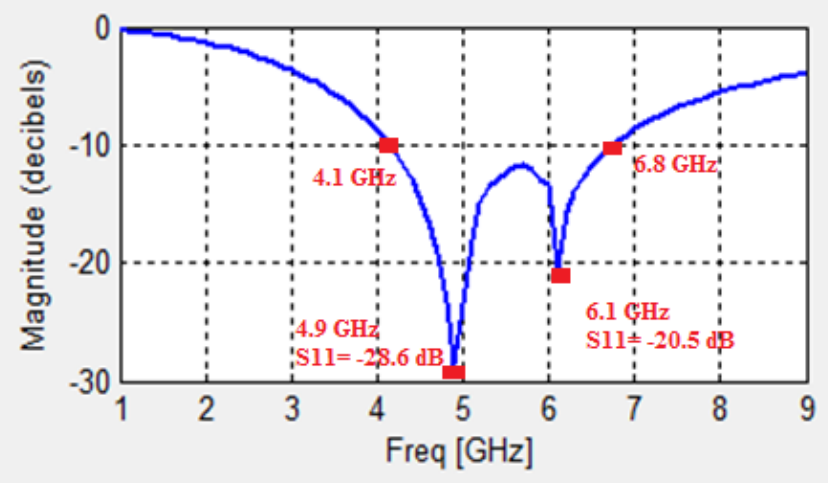

Fig-11: Return loss $\left(S_{11}\right)$ plot of equivalent circuit model for rectangular slotted MPA

\section{CONCLUSIONS}

The series RLC resonant circuit is the easiest method to realize equivalent circuit modeling of Microstrip patch antennas. The desired $S_{11}$ response can be achieved by varying the component values of RLC circuit. Therefore, it can be concluded that Microstrip patch antenna $S_{11}$ response can be equivalently modelled using series RLC resonant circuits of suitable component values in parallel fashion.

\section{REFERENCES}

[1]. Ritu Goyal, Y.K. Jain, Compact Bow Shape Microstrip Patch Antenna with Different Substrates: Proceedings of 2013 IEEE Conference on Information And Communication Technologies (ICT), 2013.

[2]. Ramesh Garg, Prakash Bhartie, Inder Bahl, Apisak Ittipiboon, “ Microstrip Antenna Design Handbook”, pp. 168, 253-316 Artech House Inc. Norwood, MA,2001.

[3]. Indrasen Singh, Dr.V.S.Tripathi, "Microstrip Patch Antenna and its Applications: a Survey", International Journal of Computer Technology and Applications, ISSN2229-6093, Vol. 2, No. 5, 1595-1599

[4]. C.A. Balanis, "Antenna Theory Analysis and Design", 3rd Edition, New Jersey, John Wiley and Sons, 2005.

[5]. Parul Bansal, Ekambir Sidhu, Sonia Goyal, "Comparative Study of Notched Circular Slotted and Rectangular Slotted Microstrip patch antennas (MPA) for wideband applications", International Journal of Engineering Research and Applications (IJERA), ISSN: 2248-9622, National Conference on Advances in Engineering and Technology (AET- 29th March 2014).

\section{BIOGRAPHIES}

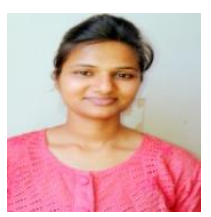

Parul Bansal is pursuing M.Tech (Final Year) in Department of ECE at Punjabi University, Patiala. Her current topic of research is design, analysis and equivalent circuit modeling of Microstrip patch antenna.

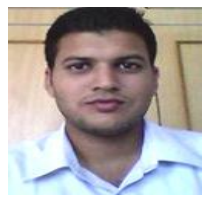

Er. Ekambir Sidhu is Assistant Professor in Department of ECE at Punjabi University, Patiala. His area of specialization is Antenna and Wireless Sensors.

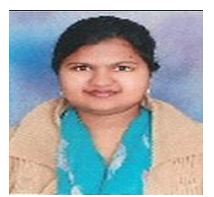

Er. Sonia Goyal is Assistant Professor in Department of ECE at Punjabi University, Patiala. Her area of specialization is Antenna and Wireless Communication. 